\title{
Laser yellowing effect: study of the nanophases created by laser irradiation of synthetic black crusts using transmission electron microscopy (TEM) and electron paramagnetic resonance (EPR) spectroscopy
}

\author{
Marie Godet ${ }^{1,2,3 *}$, Véronique Vergès-Belmin ${ }^{1}$, Christine Andraud ${ }^{2}$, Mandana \\ Saheb $^{4}$, Judith Monnier ${ }^{5}$, Eric Leroy ${ }^{5}$, Julie Bourgon ${ }^{5}$, Laurent Binet ${ }^{6}$ \\ 1 Laboratoire de Recherche des Monuments Historiques (CRC-LRMH USR 3224), 29 rue de Paris \\ 77420 Champs-sur-Marne, France \\ 2 Centre de Recherche et Conservation des Collections (CRC-CRCC USR 3224), 36 rue Geof- \\ froy-Saint-Hilaire - CP 21, 75005 Paris, France \\ 3 SILLTEC, Domaine Technologique de Saclay, 4 rue René Razel, 91400 Saclay, France \\ 4 Laboratoire Interuniversitaire des Systèmes Atmosphériques (LISA, UMR CNRS 7583) Université \\ Paris-Est Créteil and Université Paris-Diderot, 61 avenue du Général de Gaulle, 94010 Créteil Cedex, \\ France \\ 5 Institut de Chimie et des Matériaux Paris-Est (ICMPE, UMR 7182 CNRS-UPEC), Université \\ Paris-Est, 2/8, rue Henri Dunant, 94320 Thiais, France \\ 6 Institut de Recherche de Chimie ParisTech (IRCP), 11 rue Pierre et Marie Curie, 75005 Paris, \\ France \\ * Corresponding author: msgodet@gmail.com
}

\begin{abstract}
Nd:YAG Q-Switched laser cleaning at $1064 \mathrm{~nm}$ can sometimes lead to a more yellow appearance of the stone surface in comparison with other cleaning techniques. The yellow hue can originate from different contributions among which the presence of nano-sized residues generated by the laser interaction with the surface materials to be eliminated. In this study, the nature of such residues has been investigated. The analyzed materials are (i) particles collected from a pure gypsum reference plate; (ii) a synthetic crust, composed of $80 \mathrm{wt} \%$ natural black crust and $20 \mathrm{wt} \%$ synthetic gypsum; (iii) particles ejected from the synthetic crust during laser irradiation. Optical, scanning electron and transmission electron microscopies were used to link color changes at the macro-scale to morphology changes at the submicron- and nano-scales. Chemical composition was also obtained at the nano-scale using TEM coupled with energy dispersive X-ray (EDX) spectroscopy. This multi-scale approach was combined with electron paramagnetic resonance spectroscopy (EPR) analysis at low and room temperatures to examine the possible presence of iron-containing species presenting particular magnetic properties in the sample before and after irradiation. Under laser irradiation, both the crust sample and the ejected gypsum particles take a yellow color. This color shift can be linked with morphology changes occurring at the nano-scale: gypsum crystals from the reference plate show a smooth surface, while those coming from the synthetic black crust are, after irradiation, covered by many spherical nanoparticles and a rough nano-layer ranging from less than $20 \mathrm{~nm}$ to more than 100
\end{abstract}


$\mathrm{nm}$. TEM-EDX analysis reveals that the two types of nanostructures have a chemical composition very similar to that of iron-rich coal fly-ashes called magnetospheres or ferrospheres. It is suggested that laser irradiation induces a transformation of micrometric size fly-ashes present in the black crust into different types of nanostructures having a chemical composition similar to the one of ferrospheres. EPR analysis demonstrates the presence of ferri-ferro-superparamagnetic species both before and after irradiation, thus indicating that nanosized magnetic iron compounds probably corresponding to magnetite or maghemite oxides are present in the black crust, most probably crystallized on the surface or within the fly-ashes microparticles. This study brings to light the contribution of fly-ashes to the laser induced yellowing process.

Keywords: laser, cleaning, black crust, yellowing, fly-ashes, TEM, EPR

\section{Introduction}

Monuments or sculptures generally get a quite different appearance when cleaned by microsandblasting, water based chemicals or Nd:YAG Q-switched laser at 1064nm. The laser-cleaned objects have generally a darker and sometimes a more yellow appearance. A significant number of investigations have been performed to date on the topic [1]: it is now admitted that the phenomenon may be linked to several causes, among others an unveiling of strongly colored surfaces hidden by black surface layers [2]. Another hypothesis raised in the 2000's links the specific color to the presence of nanometer-size particles [3]. These particles clearly originate from the transformation of phases present in the black crust itself, and this would maybe explain why the laser-linked yellowing phenomenon is not ubiquitous, as the composition of black crusts may substantially change from one place to another.

Furthermore, several causes of yellowing may accumulate in some cases: Vergès-Belmin et al. [4] links for instance the strong yellow color of sculptures at Chartres Cathedral, both to the preservation of a past colored surface treatment and the presence over it of a very shallow layer linked to the laser-substrate interaction, and impossible to put in evidence by ordinary investigation tools such as optical microscopy and SEM-EDX.

The black crust contribution to the yellowing process has been recently further investigated by De Oliveira et al. [5]. Diffuse reflectance spectroscopy coupled with Raman analyses were performed on synthetic black crusts elaborated with powdery deposits originating from the Saint-Denis basilica in France. This monument dates back from the $13^{\text {th }}$ century and is located close to Paris, in an area badly impacted by industrial pollution during the $19-20^{\text {th }}$ centuries. The analytical results suggest that the yellow appearance obtained upon laser irradiation is linked to the preservation of goethite $(\alpha-\mathrm{FeOOH})$ or the formation of a mineral having a similar spectral signature in the visible range.

Although this study and those produced previously by different authors [3,6-8] have established some major clues about the black crust contribution to the yellowing phenomenon, the exact nature of the material generated by laser treatment of black crust and contributing to the yellow color is still unknown. Indeed, the neo-formed objects are present in a very low amount - below the detection threshold of many analytical tools - and are nano-sized: they require, to be characterized, the use of a specific and adequate analytical protocol. 
In this study, we follow a previously published methodology [9] to examine the morphology and the chemical composition of the neo-formed objects produced by irradiation of a synthetic black crust. The strategy consists in a multi-scale approach. Optical microscopy (OM) imaging is first performed to characterize the color of the sample at the macro-scale. Scanning electron microscope (SEM) imaging is carried out in a second step to study the morphology at the submicron-scale and eventually transmission electron microscopy (TEM) coupled with energy dispersive $\mathrm{X}$-ray spectroscopy (EDX) analysis is performed to obtain morphology information at the nano-scale in addition to chemical characterization. Electron paramagnetic resonance (EPR) spectroscopy helps to identify the unknown material by giving information on the nature and size of some components of the black crust presenting particular magnetic properties.

\section{Materials and methods}

\subsection{Materials}

Synthetic crusts are elaborated following the same procedure as the one described in De Oliveira et al. [8] but using a natural black crust collected at the Saint-Denis Basilica instead of hematite. The natural crust is a coherent, black, 5-10 mm thick material. It has a framboidal shape and was collected in
2001 in an area of the monument protected from the rain, and situated ca. 30meters high from the ground. Its composition is presented in the Table 1 (De Oliveira et al. [5]).

\section{Sample preparation}

Crust fragments are first crushed into powder and sieved through a $100 \mu \mathrm{m}$ sieve before being mixed with calcium sulphate hemihydrate $\mathrm{CaSO}_{4} \cdot 0.5 \mathrm{H}_{2} \mathrm{O}$ (ALDRICH $97 \%$ ) in the proportions $80: 20 \mathrm{wt} \%$ (natural crust: hemihydrate). A gypsum plate is then prepared from a mixture of hemihydrate and water poured on a $76 \times 26 \mathrm{~mm}^{2}$ glass slide. The dry mixture hemihydrate/black crust is sprinkled over the fresh and still wet plate through a coarse-meshed sieve (about 1 $\mathrm{mm}$ ). The remaining water in the plate will lead to the crystallization of a coherent black gypsum crust the microstructure of which is very close to real one: a gypsum crystals matrix embedding diverse particles, with an irregular surface and a dark grey color. The crust is then left to dry for 24 hours. Apart from its microstructure, this type of sample is interesting because all the contributions from the substrate (natural stone possibly covered by colored layers) - to the laser yellowing effect are avoided.

\section{Laser irradiation}

The crust samples are then irradiated with a Nd:YAG laser (BM industries). The irradiation conditions have been chosen because

Table 1. Saint-Denis Basilica black crust chemical composition

\begin{tabular}{ccccc}
\hline $\mathrm{C}^{*}\left({ }_{\mathrm{wt}} \%\right)$ & $\mathrm{N}^{*}\left({ }_{\mathrm{wt}} \%\right)$ & $\mathrm{S}^{*}\left(_{\mathrm{wt}} \%\right)$ & $\left.\mathrm{Fe}^{* *}{ }_{\mathrm{wt}} \%\right)$ & $\mathrm{CO}^{3-\star * \star}\left({ }_{\mathrm{wt}} \%\right)$ \\
\hline 2.96 & $<0.01$ & 10.83 & 0.74 & $<1$ \\
\hline
\end{tabular}

${ }^{\star} \mathrm{C}-\mathrm{H}-\mathrm{N}-\mathrm{S}$ elementary analyses, ${ }^{* *}$ inductively coupled plasma atomic emission spectroscopy (ICP-AES), ${ }^{* *}$ differential thermal and thermogravimetric analyses coupled with mass spectroscopy (DTA-TGA-MS) 
they are similar to those used by conservators. The laser is operating at a wavelength of $1064 \mathrm{~nm}$ and produces discrete pulses of laser energy up to $0.4 \mathrm{~J}$ with a pulse length of $15 \times 10^{-9}$ seconds ( $15 \mathrm{~ns}$ ). The pulse is delivered using an articulated mirrored arm and a handpiece equipped with a $70 \mathrm{~cm}$ focal converging lens. The fluence used is slowly increasing from 0.2 to $1 \mathrm{~J} . \mathrm{cm}^{2}$ during the treatment with a frequency of $10 \mathrm{~Hz}$ and a duration of irradiation of three minutes per $\mathrm{cm}^{2}$. In other words, about 1800 pulses per square centimeter are used to clean the samples. The surface of the samples is water sprayed once before irradiation, once after $1 \mathrm{~min} 30 \mathrm{~s}$ and once again after $2 \mathrm{~min}$ $45 \mathrm{~s}$. Each spray corresponds to $80 \mathrm{mg}$ of water over ca $7.5 \mathrm{~cm}^{2}$ (approx. $0.01 \mathrm{~g} / \mathrm{cm}^{2}$ ). The ablated particles are collected both on a clean glass slide $(76 \times 26 \mathrm{~mm})$ and on a round adhesive carbon tab (diameter: 6 $\mathrm{mm}$ ) disposed vertically and close to the samples. The slide and the carbon tab are then stored in an airtight box to prevent contamination.

In order to have a reference material, a white synthetic gypsum plate $76 \times 26 \mathrm{~mm}^{2}$ is elaborated and its surface is gently scraped using a scalpel to collect a little amount of reference gypsum particles which are put on a carbon tape for analysis.

\subsection{Methods}

The morphology and color of the crusts before and after irradiation as well as the ablated particulate materials have first been observed with a Digital Microscope 3D VHX-5000 from KEYENCE Corporation.

Scanning electron microscopy (SEM) is then used to study the morphology of the ablated particles at a micron- and submicron-scale. The SEM observation is per- formed with a SEM-FEG MERLIN at $15 \mathrm{kV}$. The adhesive carbon tabs covered by ablated particles or reference ones are metalized with $4 \mathrm{~nm}$ of palladium/platinum and then put directly into the microscope.

Transmission electron microscopy (TEM) analysis is finally used to identify the morphology and the chemical composition of the ablated particles at a nano-scale. TEM analysis is performed at $200 \mathrm{kV}$ with a FEI TECNAI F20 equipped with a STEM device fitted to an EDX spectrometer EDAX R-TEM Sapphire. The EDX capability is used to determine the chemical compositions of the particles. The samples are prepared by rubbing gently the surface of the glass slide with a copper grid covered with a holey amorphous carbon film. As gypsum is a beam sensitive material a cooler sample holder is being used at liquid nitrogen temperature $\left(-172^{\circ} \mathrm{C}\right)$ in order to limit the sample degradation during the analysis.

Electron paramagnetic resonance spectroscopy (EPR) is used to study the possible presence of paramagnetic defects or ferro/ ferri-magnetic materials in the sample before and after irradiation. Pure synthetic gypsum powder has also been analyzed to serve as a reference. The analyses were conducted at two temperatures: ambient (RT) and low $(10 \mathrm{~K})$ to seek for superparamagnetic effect and thus highlight the presence of superparamagnetic species in the samples. EPR is performed on a Bruker ELEXSYS E500 spectrometer working at X band (9.4 $\mathrm{GHz}$ ) and equipped with a SHQ resonator. A $100 \mathrm{kHz}$ modulation of the magnetic field was used for lock-in detection so that the EPR signal appears as absorption derivatives with respect to the magnetic field. A few milligrams of bulk sample are necessary for the analysis. The EPR spectra are normalized to the mass of the samples. 


\section{Results}

\subsection{Optical microscope}

During laser irradiation the surface of the crust sample becomes yellow and a lot of particles are ablated and get on the glass slide.

In the following paragraphs, we will first describe the natural crust sample itself and then the ablated particles.

\section{The crust}

Before irradiation, various micro-sized particles entrapped in a matrix of white or transparent crystals that we interpret as being gypsum are observed on the crust surface (see Fig. 1). These micro-particles are black to yellow and red ochre colored, shapes either rod-like, angular, round or botryoidal and sizes ranging from less than $10 \mu \mathrm{m}$ to more than $50 \mu \mathrm{m}$. The size of the gypsum crystals ranges from a few microns to a few hundred microns with a form of rods, platelets or more irregular sub angular aggregates.

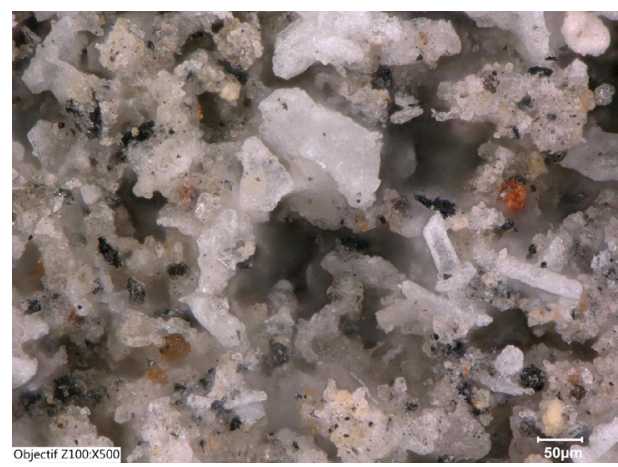

Fig. 1. Optical micrograph of a synthetic black crust before irradiation.

After laser irradiation, a strong yellow discoloration is noticed on the crust surface (see Fig. 2). A large proportion of it has been ablated and the remaining material shows a clearly yellow color. The same micro-sized

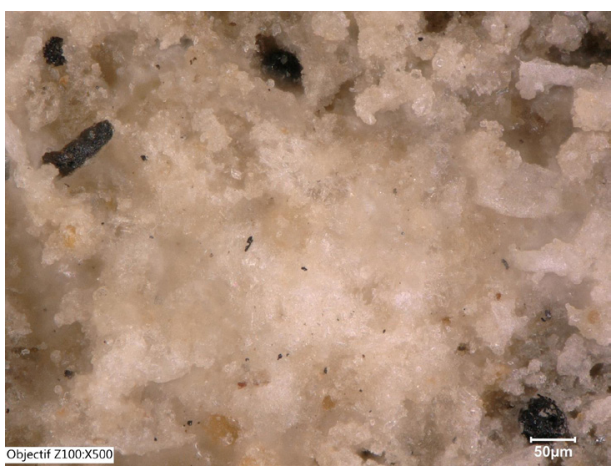

Fig. 2. Optical micrograph of a synthetic black crust after irradiation.

particles as those described before irradiation are still visible but in a smaller amount.

\section{The ablated particles}

The reference gypsum crystals take on the form of white transparent rods or platelets ranging from less than 10 microns to more than a few hundred microns; they often form irregular aggregates measuring a few tens to a few hundred of microns (see Fig. 3).

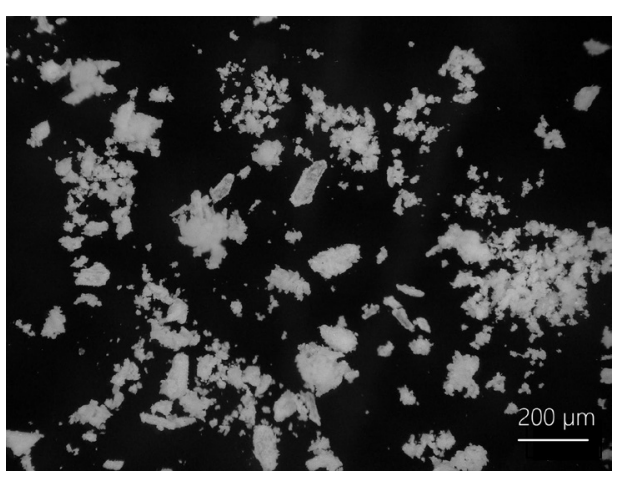

Fig. 3. Optical micrograph of gypsum crystals originating from a synthetic white gypsum plate.

The observation of the laser ablated particles reveals the presence of gypsum crystals having the same yellow color and the same sizes and shapes as the ones of the 
crust they originate from. We can also notice the presence of the same various micro-sized particles as the ones already observed in the natural crust, before and after irradiation (see Fig. 4 and Fig. 5). Though the shapes and sizes of these ablated crystals are similar to the ones of pure gypsum crystals, the color is not the same as we observe yellow ablated crystals whereas the pure crystals are white.

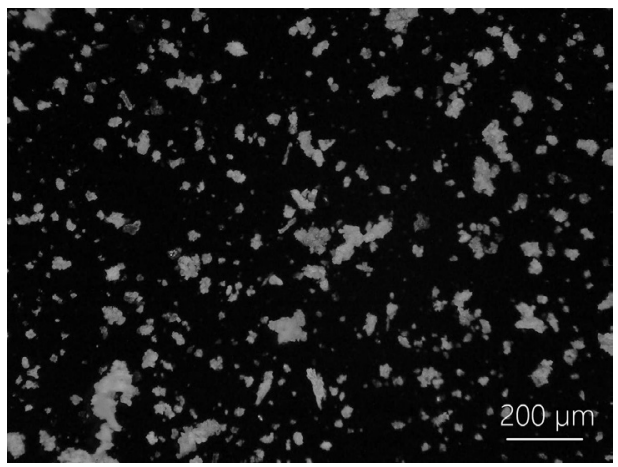

Fig. 4. Optical micrograph of ablated particles during irradiation of synthetic black crust.

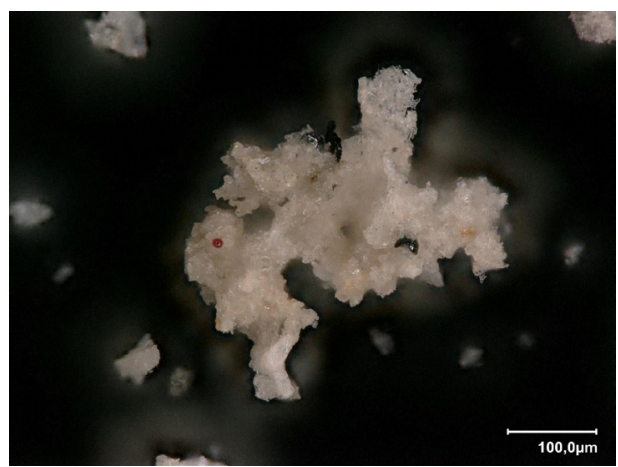

Fig. 5. Optical micrograph of ablated yellow gypsum crystals aggregate and various colored microparticles.

\subsection{Scanning electron microscopy}

SEM observation was conducted on non-irradiated reference gypsum crystals (see Fig.6) and on the ablated particles (see
Fig. 7) in order to determine the morphology differences induced by laser irradiation at the submicron-scale.

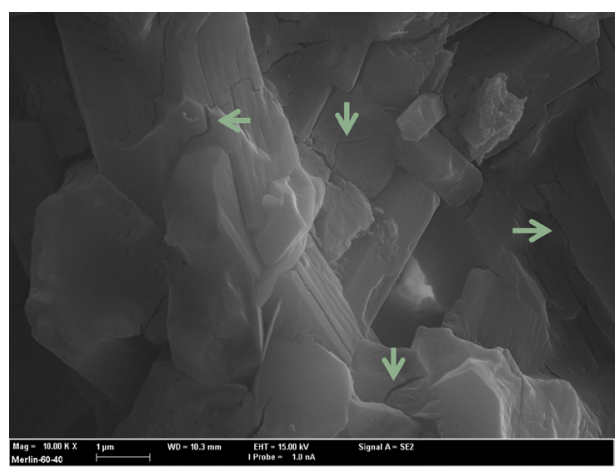

Fig. 6. SEM-SE picture of non-irradiated reference gypsum crystals; green arrow: cracks induced by the electron beam.

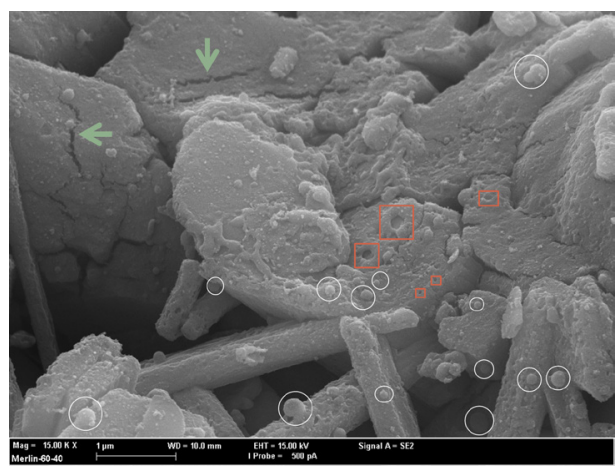

Fig. 7. SEM-SE picture of ablated gypsum crystals after laser irradiation; white circle: spherical nanoparticles; red square: nano-cavities; green arrow: cracks.

\section{Non-irradiated reference gypsum crystals}

The reference gypsum crystals take on the form of smooth rods and platelets entangled together. Their size is a few microns. The cracks observed in some of those crystals are an artifact induced by the electron beam.

\section{The irradiated ablated particles}

After laser irradiation, the surface of the ablated crystals looks significantly different: 
the crystals appear covered by spherical nanoparticles (see Fig. 7) presenting a huge range of sizes from less than a few tens of nanometers to a few hundred nanometers. In addition, the surface of the crystals is not smooth as the reference one but it presents a rough nano-layer. Nano-cavities can be observed at the surface of some crystals. Micro-cavities have also been observed in other areas. The cracks observed in some crystals are again an artifact induced by the beam.

\subsection{Transmission electron microscopy}

TEM analysis was conducted to explore the morphology of the ablated crystals at the nano-scale. Gypsum crystals are irregularly covered by spherical nanoparticles of various sizes ranging from less than $10 \mathrm{~nm}$ to more than $200 \mathrm{~nm}$. A large part of the gypsum crystals presents an irregular surface at the nanoscale (see Fig. 8 and Fig. 9).

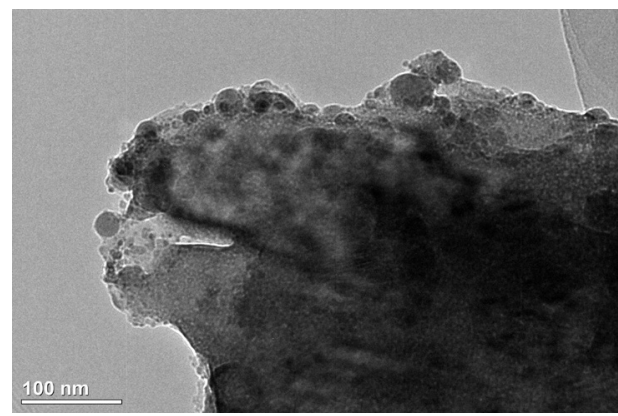

Fig. 8. TEM-BF picture of a surface of an ablated gypsum crystal presenting a rough nanolayer and covered by nanoparticles.

A large amount of isolated nano-spheres is also found on the copper grid. They have probably been detached from the gypsum rods or platelets when we rubbed the copper grid on the glass slide surface. Some nanospheres show a porous morphology with nano-pores measuring less than $50 \mathrm{~nm}$ (see Fig. 10).

The chemical composition of the nanostructures of interest was determined using EDX. All the nanoparticles present similar

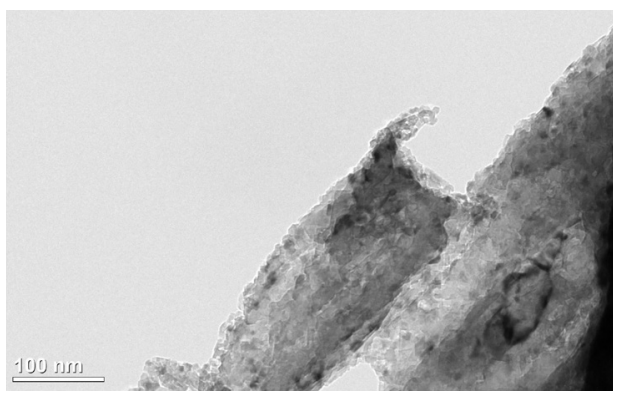

Fig. 9. TEM-BF picture of a surface of an ablated gypsum crystal presenting a rough nanolayer.

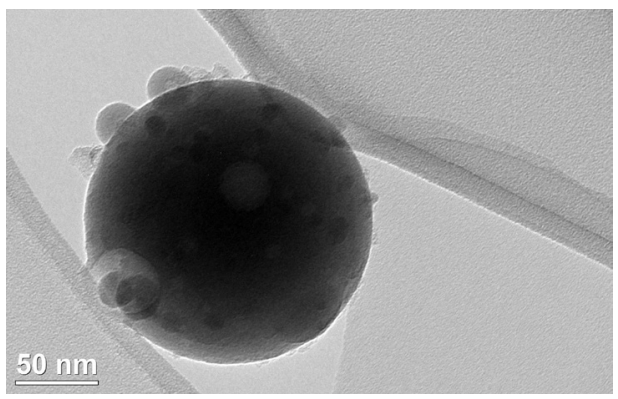

Fig. 10. TEM-BF picture of an isolated and porous nanosphere covered by smaller nanospheres.

compositions with different proportions of each element: a majority of oxygen, silicon, aluminum and iron, and various small amounts of magnesium, potassium, titanium, calcium, sulfur, phosphorus. The rough nanolayer has the same chemical composition (see Tab. 2).

Table 2. Chemical composition of the nanostructures observed on the ablated crystals after irradiation

\begin{tabular}{ll}
\hline Major elements & $\mathrm{O}, \mathrm{Al}, \mathrm{Si}, \mathrm{Fe}$, sometimes $\mathrm{Ca}$ \\
\hline Minor elements & $\mathrm{Mg}, \mathrm{K}, \mathrm{Ti}, \mathrm{Ca}, \mathrm{S}, \mathrm{P}$ \\
\hline
\end{tabular}




\subsection{Electron paramagnetic resonance spectroscopy (EPR)}

Electron paramagnetic resonance spectroscopy (EPR) has been conducted to study the possible presence of paramagnetic defects or ferro/ferri-magnetic materials in the black crust before and after irradiation. The reference gypsum has no EPR signal meaning that there are no paramagnetic defects or ferro/ferri-magnetic materials in the gypsum crystals.
At $10 \mathrm{~K}$, the intensity of the resonance at $\mathrm{g}=2.006$ corresponding to the carbonaceous matter species is much higher than at RT. We note the apparition of a resonance at $\mathrm{g}=4.27$, assigned to isolated $\mathrm{Fe}^{3+}$ in low symmetry sites. The resonance line at $\mathrm{g}=2.16$ has become larger due to the temperature change. In addition, we can notice a shift of this line towards low magnetic field values (see Fig. 12). This broadening and shift of the resonance are characteristic of ferri/ ferro-superparamagnetic materials [12].

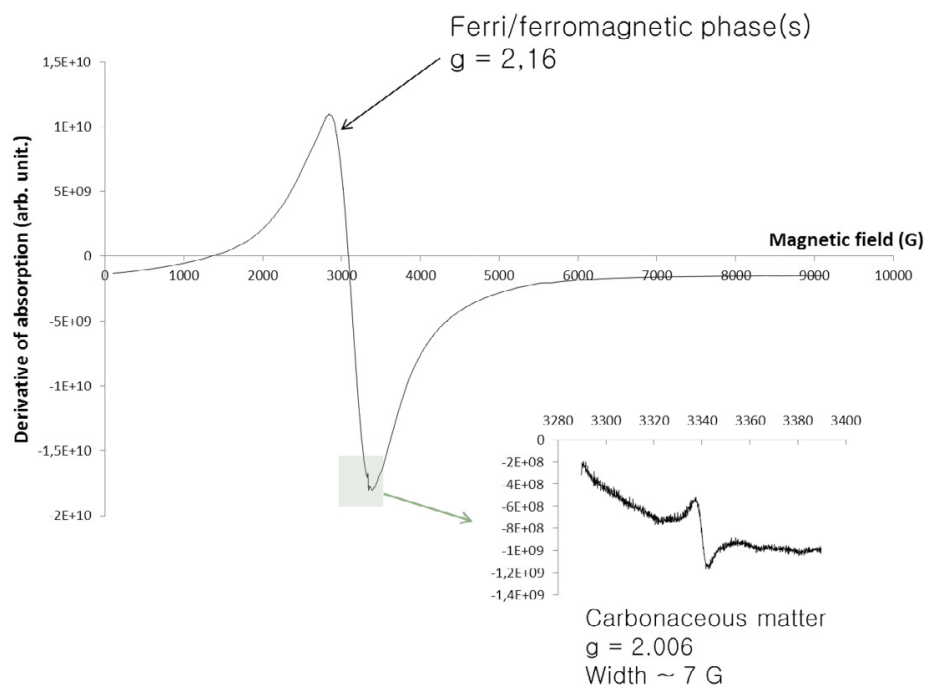

Fig. 11. EPR spectrum of the non-irradiated synthetic black crust at Room Temperature (RT).
Before laser irradiation, we can notice the presence of two main lines on the room temperature EPR spectra of black crust at $g$ $=2.16$ and $g=2.006$ (see Fig. 11). The first consists of a large resonance line given by the presence of ferri/ferromagnetic material corresponding to $\mathrm{Fe}^{3+}$ ions disposed in randomly oriented iron oxides such as magnetite-maghemite particles [10]. The second line at $g=2.006$ has a width of about $7 \mathrm{G}$ and thus it highlights the presence of carbonaceous matter within the black crust [11].
After laser irradiation, the EPR spectrum at RT shows one main line at $\mathrm{g}=2.18$ corresponding to the presence of ferri/ferromagnetic material. The intensity of the resonance is lower than the one of the non-irradiated black crust meaning that there is a lower amount of the ferri/ferromagnetic material after laser treatment. The resonance at $g=2.006$ linked with the presence of carbonaceous matter is no longer visible (see Fig. 13).

At $10 \mathrm{~K}$, we notice the resonance at $\mathrm{g}=$ 4.27 corresponding to isolated $\mathrm{Fe}^{3+}$ in low 

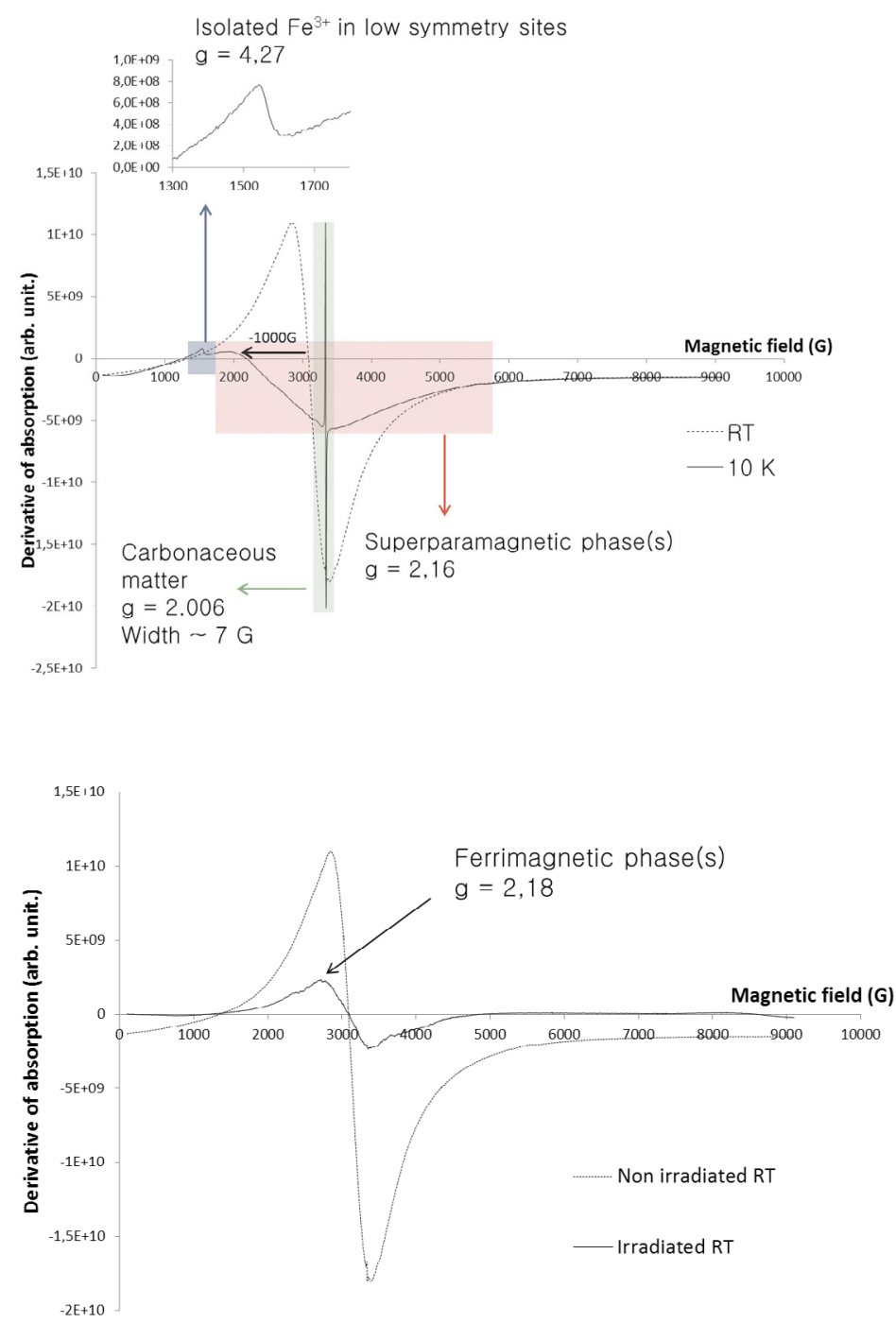

Fig. 12. EPR spectra of the non-irradiated synthetic black crust at RT and $10 \mathrm{~K}$.
Fig. 13. EPR spectra of the irradiated synthetic black crust at RT (in comparison with non-irradiated black crust). symmetry sites, as already seen for the non-irradiated black crust. The resonance line at $\mathrm{g}=2.18$ has also become larger due to the temperature change and we can notice a shift of the line towards low magnetic field values. This broadening and shift of the resonance ascertain the presence of ferri/ ferro-superparamagnetic material within the laser irradiated natural crust. One other line is apparent at $\mathrm{g}=2.006$ corresponding to carbonaceous matter already described in the non-irradiated crust (see Fig. 14).

If we compare the non-irradiated black crust to its irradiated counterpart at $10 \mathrm{~K}$, we can see that the intensities of the resonances corresponding to the ferri/ferromagnetic 


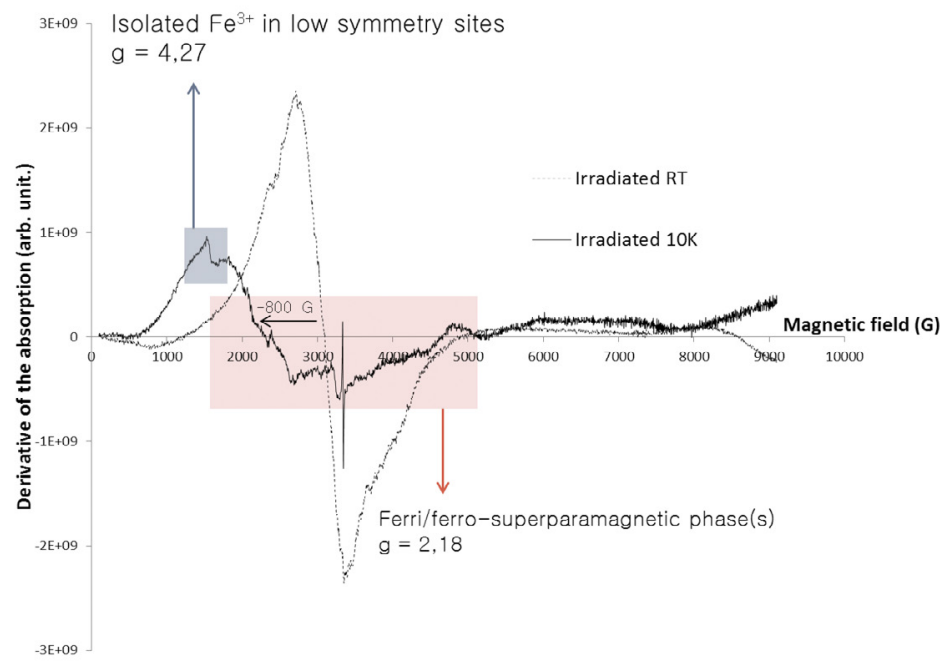

Fig. 14. EPR spectra of the irradiated synthetic black crust at RT and $10 \mathrm{~K}$.

phases $(\mathrm{g}=2.18)$ and to the carbonaceous matter $(\mathrm{g}=2.006)$ have decreased significantly during irradiation (see Fig. 15).

In conclusion, EPR analysis has highlighted the presence of superparamagnetic iron oxides, $\mathrm{Fe}^{3+}$ ion in low symmetry sites and carbonaceous matter in Saint-Denis black crust. After laser irradiation, all three are still present but in lower quantities.

\section{Discussion}

Particles such as those found in the Saint-Denis crust are commonly found in black crusts and have been extensively studied [13-20]: fly-ashes, iron oxides, organic materials, carbonaceous particles, clay minerals, oxalates etc. may all be part of a black crust. Iron compounds are of par-

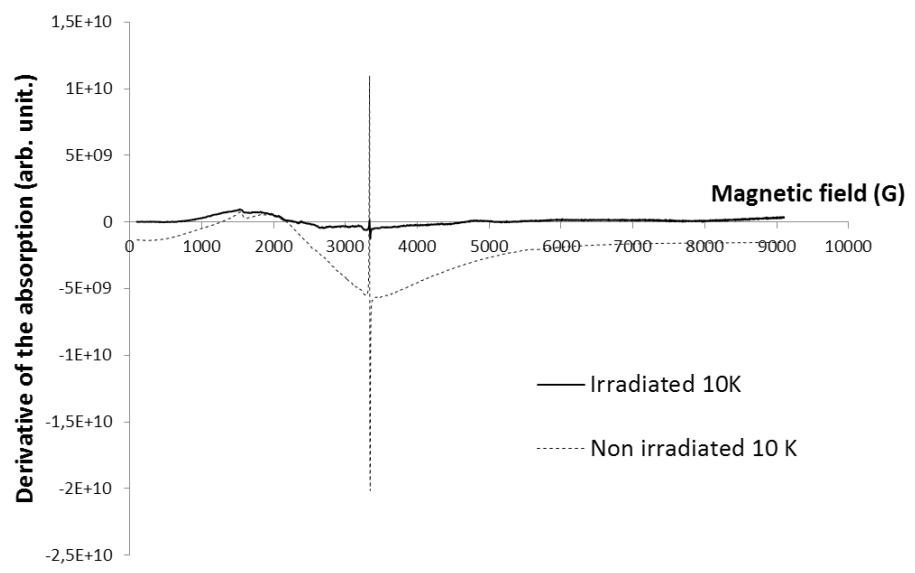

Fig. 15. EPR spectra of the irradiated synthetic black crust at $10 \mathrm{~K}$ (in comparison with non-irradiated black crust). 
ticular interest as they are known to strongly react with the laser beam [21]. They were found to be present in black crusts in the form of hematite $\alpha-\mathrm{Fe}_{2} \mathrm{O}_{3}[5,22]$, goethite a-FeOOH [5], magnetite $\mathrm{Fe}_{3} \mathrm{O}_{4}$ [23], ferrihydrite $\alpha-\mathrm{Fe}_{2} \mathrm{O}_{3} \cdot 1.8 \mathrm{H}_{2} \mathrm{O}$ and jarosite $\mathrm{KFe}_{3}\left(\mathrm{SO}_{4}\right)$ $(\mathrm{OH})_{6}$ [24]. In black crusts, iron is always less than a few weight percent $[20,25,26]$, and in our case, the iron oxide content is $0.74 \mathrm{wt} \%$ [5]. The EPR analysis performed in this study confirms the presence of iron in the Saint Denis crust. It also reveals the existence of isolated $\mathrm{Fe}^{3+}$ in low symmetry sites in addition to ferri or ferro-superparamagnetic species that we interpret as nano-sized - usually smaller than $50 \mathrm{~nm}$ according to Griscom et al. [10] - magnetite $\mathrm{Fe}_{3} \mathrm{O}_{4}$ and/or maghemite $\gamma-\mathrm{Fe}_{2} \mathrm{O}_{3}$. These results are in line with a Mössbauer study by Steger [23] showing that the iron contained in a black crust is partly localized in particles of magnetite $\mathrm{Fe}_{3} \mathrm{O}_{4}$ and partly in a poorly crystallized $\mathrm{Fe}^{3+}$ mineral.

Once the synthetic black crust is irradiated, optical microscopy reveals that the gypsum crystals either at the surface of the crust or ejected from it have turned from white to yellow. This color shift can be correlated with morphology changes observed by SEM on the laser ablated particles: gypsum crystals from the reference plate show a smooth surface, while those coming from the synthetic black crust are, after irradiation, covered by spherical nanoparticles and a rough nano-layer. These observations are very similar to those already made on laser irradiated model crust samples $[3,8,9]$. Actually, the first studies on the interactions between the laser beam and black crust have begun with simplified model crust samples as natural black crusts were considered as too heterogeneous and complex. In their study on laser yellowing, Klein et al.
[3] detected spherical nanoparticles after laser irradiation at the surface of a ternary model crust containing hematite $\alpha-\mathrm{Fe}_{2} \mathrm{O}_{3}$, graphite and gypsum. More recent studies focused on binary model crusts containing only hematite $\alpha-\mathrm{Fe}_{2} \mathrm{O}_{3}$ and gypsum have put in evidence that both the model crusts substrate and the laser ablated material were covered, after irradiation, by spherical nanoparticles and by a rough nano-layer $[8$, 9]. The laser irradiation thus appears to have an analogous effect on the morphology a nano-structuration of the gypsum crystals surface - whether the crystals come from a model or from a natural crust.

TEM-EDX was used in this study, both to image the ablated material at the nano-scale and to analyze its chemical composition on an area of a few nanometers. It is to be noticed that the extremely small size of the neo-formed phases on our samples would not have allowed a proper SEM-EDX anal$y$ sis, since the interaction volume of the electron probe is in the micrometer range for this technique. TEM imaging confirms the presence of spherical nanoparticles of various sizes, and of a rough nano-layer or nano-residues which can be observed on the surface of several gypsum crystals. TEM-EDX analysis reveals that all the nanostructures predominantly contain $\mathrm{O}$, $\mathrm{Si}, \mathrm{Al}, \mathrm{Fe}$ and little amounts of $\mathrm{Mg}, \mathrm{K}, \mathrm{Ti}, \mathrm{Ca}$, $\mathrm{S}, \mathrm{P}$ etc. This composition is very similar to the one of glassy fly-ashes originating from coal combustion plants $[13,14,17,27,28]$, being described as $2-40 \mu \mathrm{m}$ glassy aluminosilicate spheres containing $\mathrm{Mg}, \mathrm{Fe}, \mathrm{Ti}, \mathrm{K}$ as other elements $[19,27]$. More specifically, the nanostructures of interest in the present study have a composition close to that of the so-called magnetospheres or ferrospheres, a particular type of coal fly ashes which are magnetic and enriched in iron [29]. 
An important point to note at this stage is that fly-ashes are essentially defined as micro-sized particles [30]. Seames [31] and Buhre et al. [32] have shown that the PM1 ultra fine fraction of fly-ashes - measuring less than $1 \mu \mathrm{m}$ diameter - represents less than $1_{\text {wt }} \%$ of the total amount of ashes generated by the coal combustion. Yet the TEM analysis we conducted reveals the presence of a large amount of nano-sized fly-ashes covering the ablated gypsum particles. These nanoparticles may have been generated by the interaction between the laser beam and the micrometer-sized fly-ashes present in the black crust before irradiation. This hypothesis is supported by the SEM observation of round cavities at the surface of the gypsum crystals. These micro- and nano-cavities may be the result of the interaction of fly-ashes with the laser beam. A characterization of the natural crust at the nano-scale would thus be useful to check if nanometric fly-ashes type particles are already present before irradiation.

Anyhow, this is the first time that a link between the yellowing phenomenon and the fly-ashes present in black crusts is highlighted. It is not that surprising as fly-ashes contain iron species which are known to contribute to the yellowing effect. Our results also show that the laser-generated nanostructures have a different chemical composition if the irradiated material is mainly a real black crust material as in the present study, or is a model composed of a mixture of hematite and gypsum as in former studies [9]. In the case of model crusts, the nanostructures are found to contain $\mathrm{O}, \mathrm{Fe}, \mathrm{Ca}, \mathrm{S}$ in various proportions whereas for the synthetic black crust, the nanostructures predominantly contain $\mathrm{Si}, \mathrm{Al}, \mathrm{O}, \mathrm{Fe}$.

This seems to indicate that the phases generated during laser irradiation are different depending on if the irradiated material contains iron oxides or fly-ashes. However, in both cases a yellow color is produced at the macro-scale.

\section{Conclusion}

A specific multi-scale analytical methodology has enabled us to reveal for the first time the presence of two types of nanostructures at the surface of laser ablated yellow gypsum crystals - nanospheres and a rough nanolayer - the composition of which is very similar to that of iron rich coal fly-ashes (the so-called magnetospheres or ferrospheres) present in black crusts before irradiation. Our results suggest that laser irradiation induces a transformation of micro-sized fly ashes into nanostructures, having the same chemical composition.

EPR analysis demonstrates the presence of nano-sized magnetic iron compounds $(<50$ $\mathrm{nm}$ ) probably corresponding to magnetite or maghemite in the black crust, the same species being also present - in a lower amount - after irradiation. Such phases would play a key role in the reactivity of fly ashes to laser irradiation, as these species are known to strongly absorb the laser at $1064 \mathrm{~nm}$.

In any event, it is the first time that a contribution from fly-ashes to the laser yellowing effect is highlighted, opening the door for future investigations. De facto further study is currently conducted on new model crusts containing only fly-ashes and gypsum.

\section{References}

[1] P. Pouli, M. Oujja, M. Castillejo, "Practical issues in laser cleaning of stone and painted artefacts: optimisation procedures and side effects", Applied Physics A., 106 (2012) 447-464, DOI: 10.1007/ s00339-011-6696-2. 
[2] V. Vergès-Belmin, C. Dignard, "Laser yellowing: myth or reality?", Journal of Cultural Heritage, 4 (2003) 238-244.

[3] S. Klein, F. Fekrsanati, J. Hildenhagen, K. Dickmann, H. Uphoff, Y. Marakis, V. Zafiropulos, "Discoloration of marble during laser cleaning by Nd:YAG laser wavelengths", Applied Surface Science, 171 (2001) 242-251.

[4] V. Vergès-Belmin, C. De Oliveira, O. Rolland, "Investigations on yellowing as an effect of laser cleaning at Chartres Cathedral, France", in: ICOM-CC $17^{\text {th }}$ Triennial Conference Preprints, J. Bridgland, Melbourne, 2014.

[5] C. De Oliveira, V. Vergès-Belmin, J. Lafait, M. Swider, C. Andraud, A. Tournié, L. Galoisy, "Contribution of goethite to laser-induced stone yellowing", Applied Physics A., 122 (2016), DOI: 10.1007/s00339-016-9818-z.

[6] M. Gavino, B. Hermosin, V. Vergès-Belmin, W. Nowik, C. Saiz-Jimenez, "New insights on the chemical nature of stone yellowing produced after laser cleaning", in: Cultural Heritage Conservation and Environmental Impact Assessment by Non-Destructive Testing and Micro-Analysis, Van Grieken \& Janssens, Antwerp, 2005: pp. 149-157.

[7] P. Pouli, C. Fotakis, B. Hermosin, C. Saiz-Jimenez, C. Domingo, M. Oujja, M. Castillejo, "The laser-induced discoloration of stonework; a comparative study on its origins and remedies", Spectrochimica Acta Part A., 71 (2008) 932-945.

[8] C. De Oliveira, V. Vergès-Belmin, D. Demaille, P. Bromblet, "Lamp black and hematite contribution to laser yellowing: A study on technical gypsum samples", Studies in Conservation, (2015), DOI: 10.1179/2047058415Y.0000000003.

[9] M. Godet, V. Vergès-Belmin, C. Andraud, M. Saheb, J. Monnier, E. Leroy, J. Bourgon, "Laser yellowing of hematite-gypsum mixtures: a multi scale characterization", in: Science and Art: A Future for Stone, John Hughes \& Howind Torsten, Paisley 2016, pp. 785-792.

[10] D.L. Griscom, "Ferromagnetic resonance of precipitated phases in natural glasses", Journal of Non-Crystalline Solids, 67 (1984) 81-118.
[11] A. Barbon, M. Brustolon, "An EPR study on Nanographites", Applied Magnetic Resonance, 42 (2012) 197-210, DOI: 10.1007/s00723-011-0285-6.

[12] R. Berger, J.-C. Bissey, J. Kliava, H. Daubric, C. Estournès, "Temperature dependence of superparamagnetic resonance of iron oxides nanoparticles", Journal of Magnetism and Magnetic Materials, 234 (2001) 535-544.

[13] M. Del Monte, C. Sabbioni, O. Vittori, "Airborne carbon particles and marble deterioration", Atmospheric Environment, 15 (1981) 645-652.

[14] C. Sabbioni, "Contribution of atmospheric deposition to the formation of damage layers", The Science of the Total Environment, 167 (1995) 49-55.

[15] A.G. Nord, A. Svardh, K. Tronner, "Air pollution levels reflected in deposits on building stone", Atmospheric Environment, 28 (1994) 2615-2622.

[16] C. Rodriguez-Navarro, E. Sebastian, "Role of particulate matter from vehicle exhaust on porous building stones (limestone) sulfation", The Science of the Total Environment, 187 (1996) 79-91.

[17] P. Ausset, M. Del Monte, R. Lefèvre, "Embryonic sulphated black crusts on carbonate rocks in atmospheric simulation chamber and in the field: role of carbonaceous fly-ash", Atmospheric Environment, 33 (1999) 1525-1534.

[18] A. Bonazza, C. Sabbioni, N. Ghedini, "Quantitative data on carbon fractions in interpretation of black crusts and soiling on European built heritage", Atmospheric Environment, 39 (2005) 2607-2618.

[19] M. Urosevic, A. Yebra-Rodriguez, E. Sebastian, C. Cardell, "Black soiling of an architectural limestone during two-year term exposure to urban air in the city of Granada (Spain)", The Science of the Total Environment, 414 (2012) 564-575, DOI: 10.1016/j. scitotenv.2011.11.028.

[20] S.A. Ruffolo, V. Comite, M.F. La Russa, C.M. Belfiore, D. Barca, A. Bonazza, G.M. Crisci, A. Pezzino, C. Sabbioni, "An analysis of the black crusts from the Seville Cathedral: A challenge to deepen the understanding of the relationships among microstructure, microchemical features and pollution sources", Science of the Total Environment, 502 (2015) 157-166, DOI: 10.1016/j.scitotenv.2014.09.023. 
[21] S. Siano, F. Fabiani, R. Pini, R. Salimbeni, M. Giamello, G. Sabatini, "Determination of damage thresholds to prevent side effects in laser cleaning of pliocene sandstone of Siena", Journal of Cultural Heritage, 1 (2000) 47-53.

[22] S.S. Potgieter-Vermaak, R.H.M. Godoi, R.V. Grieken, J.H. Potgieter, M. Oujja, M. Castillejo, "Micro-structural characterization of black crust and laser cleaning of building stones by micro-Raman and SEM techniques", Spectrochimica Acta Part A: Molecular and Biomolecular Spectroscopy, 61 (2005) 2460-2467, DOI: 10.1016/j.saa.2004.09.010.

[23] W.E. Steger, H. Mehner, "The Iron in Black Weathering Crusts on Saxonian Sandstones Investigated by Mössbauer Spectroscopy", Studies in Conservation, 43 (1998) 49, DOI: 10.2307/1506636.

[24] A.G. Nord, T. Ericsson, "Chemical analysis of the black layers on building stone", Studies in Conservation, 38 (1993) 25-35.

[25] V. Fassina, L. Lazzarini, G. Biscontin, "Effects of atmospheric pollutants on the composition of black crust deposited on venetian marbles and stones", in: Athens, 1976, pp. 201-210.

[26] P. Maravelaki-Kalaitzaki, "Black crusts and patinas on Pentelic marble from the Parthenon and Erechtheum (Acropolis, Athens): characterization and origin", Analytica Chimica Acta, 532 (2005) 187-198, DOI: 10.1016/j.aca.2004.10.065.

[27] P. Ausset, F. Bannery, M. Del Monte, R. Lefèvre, "Recording of pre-industrial atmospheric environment by ancient crusts on stone monuments", Atmospheric Environment, 32 (1998) 2859-2863.

[28] K. Desboeufs, A. Sofikitis, R. Losno, J.-L. Colin, P. Ausset, "Dissolution and solubility of trace metals from natural and anthropogenic aerosol particulate matter", Chemosphere, 58 (2005) 195-203.

[29] R.J. Lauf, "Characterization of the mineralogy and microchemistry of fly ash", Nuclear and Chemical Waste Management, 5 (1985) 231-236.

[30] Q. Xue, S. Lu, "Microstructure of ferrospheres in fly ashes: SEM, EDX and ESEM analysis", Journal of Zhejiang University-SCIENCE A., 9 (2008) 1595-1600, DOI: 10.1631/jzus.A0820051.

[31] W.S. Seames, "An initial study of the fine fragmentation fly ash particle mode generated during pulverized coal combustion", Fuel Processing Technology, 81 (2003) 109-125, DOI: 10.1016/ S0378-3820(03)00006-7.

[32] B. Buhre, J. Hinkley, R. Gupta, P. Nelson, T. Wall, "Fine ash formation during combustion of pulverised coal-coal property impacts”, Fuel, 85 (2006) 185-193. DOI: 10.1016/j.fuel.2005.04.031. 